\title{
OS DESAFIOS VIVENCIADOS POR FAMÍLIAS DE CRIANÇAS DIAGNOSTICADAS COM TRANSTORNO DE ESPECTRO AUTISTA
}

\author{
Rachell Fontenele Alencar de Souza iD1 e Júlio César Pinto de Souza (D)2
}

\section{Resumo}

A chegada de um filho aumenta a autoestima de muitas famílias trazendo alegrias, sonhos e emoções, mas a descoberta de um transtorno pode abalar a estrutura familiar. Atualmente a medicina não dispõe de tecnologia que possa diagnosticar o Transtorno do Espectro Autista durante a gravidez. Este trabalho teve como objetivo verificar os enfrentamentos sociais destas famílias. A pesquisa apresenta uma abordagem qualitativa e quantitativa, de cunho descritivo. Como instrumento foi utilizada uma entrevista semiestruturada com 5 familiares de crianças com Transtorno de Espectro Autista, cujos dados coletados foram discutidos por meio da análise do conteúdo. No que tange aos resultados, verificou-se que 4 familiares obtiveram o diagnóstico antes de a criança completar três anos. Compreendeu-se que a idade dos genitores pode interferir nas chances de a criança apresentar 0 transtorno. Nota-se que, apesar de apresentarem o diagnóstico precoce, muitas mães relataram a dificuldade de encontrar profissionais especializados causando angustia, sofrimento e medo. Compreende-se que cada família tem suas formas de encarar a dificuldade referente ao transtorno e seus paradigmas.

Palavras-chave: diagnóstico precoce; família; Transtorno de Espectro Autista.

\section{CHALLENGES EXPERIENCED BY PARENTS OF CHILDREN DIAGNOSED WITH AUTISM}

\section{Abstract}

The arrival of a child increases the self-esteem of many families bringing joy, dreams and emotions, but the discovery of a disorder can shake this structure. Currently the medicine lacks technology that can diagnose Autism Spectrum Disorder during pregnancy. This work had as general objective to verify the social confrontations of these families. The research presents a qualitative and quantitative, descriptive approach. As a tool, a semi-structured interview applied to 5 family members of children with Autism Spectrum Disorder was used, with the data collected in the research analyzed using content analysis. Regarding the results, it was found that 4 of family members obtained the diagnosis before the child was three years old. It was understood that the age of the parents could interfere in the chances of the child presenting the disorder. It is noteworthy that, despite presenting an early diagnosis, many mothers reported the difficulty of finding specialized professionals causing distress, suffering and fear. It is understood that each family has its ways of facing the difficulty related to the disorder and its paradigms.

Keywords: Autism Spectrum Disorder; family; early diagnosis.

${ }^{1}$ Graduada em psicologia pelo Centro Universitário FAMETRO-Manaus/AM. Psicóloga clínica.

2 Mestre em e graduado em psicologia pela Universidade Federal do Amazonas. Professor de Graduação e pós-graduação do Centro Universitário FAMETRO - Manaus/AM.

(c) (1) (1) Perspectivas em Diálogo, Naviraí, v. 8, n. 16, p. 164-182, jan./abr. 2021. 


\section{Introdução}

De acordo com o Manual Diagnóstico e Estatístico de Transtornos Mentais (APA, 2013) o Transtorno do Espectro Autista (TEA) é um transtorno do neurodesenvolvimento não degenerativo, que afeta, principalmente, a comunicação verbal, não verbal e a interação social. Alguns estudos argumentam uma possível alteração genética e influência ambiental como causas para o transtorno.

O indivíduo com TEA tem dificuldade de expressar emoções e segue uma rotina como forma de ritual, apresentando comportamentos estereotipados. Os sinais mais evidentes do TEA surgem entre dois a três anos. Em alguns casos, apresentam-se entre os doze e dezoito meses de vida. Normalmente são os pais que identificam os primeiros sintomas (como uma forma estranha de agir da criança), levando-os a procurar ajuda profissional. Entretanto, o recebimento da notícia é sempre um forte impacto para os familiares.

Há diferentes modos de receber a notícia de um filho com o TEA na família. A forma de trabalhar essa informação depende muito das condições em que os pais da criança se encontram. Sentimentos de medo, culpa e angústia afloram, podendo interferir no aspecto psicológico desses pais. As dificuldades de os pais aceitarem o diagnóstico podem ser geradas pela preocupação em relação ao futuro da criança. Segundo Koegel e Cols (1992), as famílias que possuem crianças com TEA revelam um alto nível de preocupação quanto ao bem-estar de suas crianças caso eles não consigam mais prestar os devidos cuidados a elas.

Algumas famílias enfrentam preconceitos e discriminações por terem uma criança "estranha em casa", pois os comportamentos dessas crianças não são os considerados normais e aceitos pelas pessoas. Vizinhos, conhecidos e parentes são os protagonistas desse preconceito e discriminação.

Buscando-se entender melhor a temática apresentada, esta pesquisa elaborou como objetivo primário de compreender o enfrentamento social das famílias com crianças diagnosticadas com TEA.

Como contribuição, entende-se que os resultados deste artigo sensibilizarão a sociedade na desconstrução dos preconceitos existentes em relação ao indivíduo com TEA, bem como mostrar os desafios e sofrimentos vividos pelos pais de crianças com esse transtorno. No contexto acadêmico e científico, a relevância deste trabalho apresenta-se no objeto da pesquisa que foi a família da criança com TEA, pois a maior parte dos trabalhos sobre TEA tem como objeto da pesquisa o indivíduo com o Transtorno e a preocupação com o seu desenvolvimento e comorbidades. Poucos são os trabalhos que buscam estudar o sofrimento dos familiares e os desafios vividos por eles nessa jornada em busca de uma melhor qualidade de vida e desenvolvimento saudável da criança com TEA.

\section{Referencial teórico}

\subsection{A espera do filho}

A descoberta da chegada de um filho é motivo de muita alegria em todos da família principalmente dos pais. Neste momento, ambos criam em sua mente o filho perfeito com a ilusão de traços e formas que possam caracterizá-lo fazendo parecer 
com ambos. Esta imagem mental que cada um constrói em relação ao filho que ainda não nasceu vem do inconsciente representando pelas fantasias e desejos.

Segundo Vendrusculo (2014, p.8) "A notícia de que há um bebe a caminho, aponta para uma série de mudanças na vida de um casal, especialmente no que se refere em preparar a chegada do filho". Neste momento, os pais já começam a se preparar reformulando o espaço de sua residência e já imaginando o futuro do novo integrante da família. Boa parte dos pais já começam a imaginar como será esse filho, desde os traços físicos até a personalidade, projetando seus sonhos e expectativas nessa criança. Segundo Mannoni (1988, p. 18) a mãe espera que "o filho retrate os seus ideais e que seja reconhecido pelos outros como o máximo da perfeição e da beleza".

Segundo Cramer e Palácio-Espasa (1993) os sonhos e as expectativas de pais e mães em relação ao filho são parecidos, porém as mulheres vivenciam mais intensamente as transformações fisiológicas da gestação. Atualmente, o pai tem uma relação maior com o filho no período de gestação do que no passado, contudo, ainda não se compara com a convivência afetiva da mãe em relação ao filho que ainda não nasceu. Elas carregam e imaginam cada detalhe do seu filho, dão à luz e amamentam.

Com o nascimento da criança, o sentimento de euforia toma conta da família, afinal o filho "perfeito" nasceu. Segundo Klaus e Klaus (2011), após os meses de preparação a criança nasce e chega trazendo sentimento como a felicidade e a admiração. Esses sentimentos perduram durantes meses. Entretanto tais sentimentos são substituídos por preocupação e medo quando os pais percebem que a criança tem sinais e comportamentos diferentes das outras crianças da sua idade.

\subsection{Transtorno de Espectro Autista}

De acordo com a última atualização do Manual Diagnóstico e Estatístico de Transtornos Mentais (APA, 2013) o transtorno do Espectro Autista (TEA) é um transtorno do neurodesenvolvimento não degenerativo que afeta principalmente a comunicação verbal e não-verbal e a interação social. Este transtorno apresenta seus primeiros sintomas logo na infância nos seus primeiros anos de vida. Segundo o DSMV (APA, 2013, p. 56)

Os primeiros sintomas do transtorno do espectro autista frequentemente envolvem atraso no desenvolvimento da linguagem, em geral acompanhado por ausência de interesse social ou alterações sociais incomuns [...] padrões estranhos de brincadeiras [...] e padrões incomuns de comunicação

O diagnóstico do TEA é classificado em níveis com base na necessidade de apoio. O diagnóstico de classificação leve ocorre quando o paciente necessita de pouco apoio, a moderada quando necessita de um apoio substancial e o grave quando o apoio é muito substancial. Os sintomas do TEA representam um "continuum" de grau leve a grave, variando de um indivíduo para o outro, variando desde indivíduos com grandes limitações até indivíduos com manifestações muito próximas às de pessoas sem essa desordem (CAMPOS, 2015; p. 235).

A criança que possui o TEA, normalmente apresenta os primeiros sinais do transtorno nos primeiros 36 meses. Seu comportamento é diferente, bem peculiar, em relação aos outros sendo a apatia, as formas como brincam e o olhar distante os 
mais comuns. A criança com TEA ainda apresenta dificuldades no relacionamento social, como incapacidade de manter contato visual, ligação social e jogos em grupo. Segundo Bosa (2006), a maioria das crianças diagnosticadas com TEA pode melhorar com o tempo se receber todos os cuidados necessários. Contudo os problemas de interação e comunicação permanecem durante toda a vida.

Vale ressaltar que a criança com TEA pode apresentar uma hipersensibilidade em alguns dos seus sentidos como, chorar com um simples toque ou em alguns casos podem até não sentir dor nenhuma em uma queimadura.

\subsection{Impacto do diagnóstico para os pais}

O impacto do diagnóstico de autismo é a primeira dificuldade que a família irá encontrar. Após o diagnostico a família, mais concretamente a mãe, é comum existir a negação da existência de um transtorno. Esta fase de negação é um mecanismo de defesa temporário, entretanto, com o tempo a mãe e o pai aceitam o fato de terem um filho com TEA (PAÚL; FONSECA, 2001). Esse processo é um "luto simbólico" vivido pelos pais pela perda do filho "perfeito". Conforme explicado por Coll, Marchesi e Palacios (2004) ao comentarem que após receberem o diagnóstico do TEA, os pais tendem a ter sentimentos que se comparam ao do luto, pois "há sempre um sentimento de perda quando se tem um filho com deficiência". (p. 334).

Após o diagnóstico é importante que a família seja acompanhada por profissionais, pois estará assimilando a nova realidade decorrente do TEA e necessitam de orientação e esclarecimentos sobre o Transtorno que é envolto de tabus e estigmas. Segundo Sprovieri (1995), o trabalho dos profissionais junto às famílias pode favorecer o ajustamento das relações familiares, preparando-os para que enfrente adequadamente os obstáculos sugeridos em suas interrelações em função do sistema familiar estar adoecido. Ser pai e mãe neste momento significa embarcar em uma experiência complexa, repleta de dificuldades e extremas responsabilidades, pois a criança pode ser parcial ou totalmente dependente dos pais (BUSCAGLIA, 2006).

\section{Metodologia}

Trata-se de uma pesquisa de abordagem qualitativa e de cunho descritivo. Segundo Minayo e Sanches (1993, p. 247) "A relação entre quantitativo e qualitativo não pode ser pesada como oposição contraditória, é de se desejar que as relações sociais possam ser analisadas em seus aspectos mais "concretos" e aprofundadas em seus significados mais essenciais." Para Triviños (1987) Apud Corrêa e Hourneaux Jr (2008) a pesquisa descritiva exige do investigador uma série de informações sobre o que deseja pesquisar. Esse tipo de estudo pretende descrever os fatos e fenômenos de determinada realidade.

Como Instrumento foi utilizado a entrevista semiestruturada, que para Boni e Quaresma (2005), é uma combinação de perguntas, abertas e fechadas, onde o entrevistado pode dar suas opiniões sobre o assunto, seguindo um conjunto de questões já estabelecidas como uma conversa informal.

Quanto aos procedimentos de coleta dos dados foi realizado, inicialmente, contato e apresentado o projeto a Entidade onde foi realizada a pesquisa. Após o recebimento do termo de anuência da Entidade, o projeto foi submetido ao Comitê de Ética em Pesquisa. Após a provação do projeto de pesquisa foi realizado um 
segundo contato com a Entidade e iniciada a coleta de dados com os familiares voluntários e que estavam frequentando o local. É importante ressaltar que, por tratar de pesquisa com seres humanos, foram seguidas todas as determinações constantes na Resolução 466/2012 do Conselho Nacional de Saúde, seguindo todos os aspectos éticos pertinentes, inclusive aguardou-se a aprovação do projeto de pesquisa pelo Comitê de Ética em Pesquisa para iniciar a coleta de dados. Todos os participantes assinaram o Termo de Consentimento Livre e Esclarecido.

Os familiares foram ouvidos em um ambiente calmo e isolado, oferecendo discrição e segurança quanto ao sigilo das informações. Todos os dados coletados na pesquisa de campo foram analisados e discutidos, sendo resguardados os nomes dos entrevistados que foram substituídos por um código Alfanumérico (P.1, P2., P.3,...).

Os dados qualitativos foram analisados por meio da análise do conteúdo. Alguns dados quantitativos foram usados na pesquisa para contextualizar e auxiliar na discussão dos dados.

A população inicial desta pesquisa era de 10 famílias, pois era a quantidade de famílias cadastradas pela entidade onde foi feita a investigação, a época do primeiro contato. A amostragem planejada era censitária, com isso, no projeto de pesquisa, a proposta era que a amostra fosse de 10 famílias. Os critérios adotados para o levantamento da amostra foi que a família fosse voluntária, estivesse cadastrada na entidade onde se realizou a pesquisa e que o familiar tivesse uma convivência direta com a criança. Entretanto, quando iniciaram-se os contatos com os familiares, para convidá-los a participar da pesquisa, 2 famílias informaram que não poderiam participar, visto que não estavam mais frequentando a Entidade, por questões particulares, e 3 famílias não participaram por não terem comparecido nas datas e horários marcados, ressaltando que em todos os casos a data e horário foi remarcado uma vez e nas duas oportunidades as famílias faltaram. Desta forma, a amostra da pesquisa foi de 5 famílias. Conforme Teixeira (2003), a abordagem de dados enquanto etapa de investigação cientifica é relevante, pois pode significar melhores condições para o desenvolvimento de novos estudos, com base no melhor entendimento do processo.

\section{Resultados e discussões}

Os resultados a seguir equivalem às respostas dadas pelos familiares nas perguntas objetivas que buscaram levantar informações sobre os participantes, a fim de contextualizar o problema da pesquisa e apresentar argumentos para entender as opiniões e interpretações das famílias entrevistadas. Dados sobre a descoberta do transtorno e o conhecimento da família sobre o TEA contribuíram para melhor analisar as respostas das famílias nas perguntas discursivas.

\subsection{A descoberta do Transtorno}

Quando os participantes foram questionados quanto ao momento em que os pais identificaram algo de diferente no filho, verificou-se que 4 participantes da pesquisa identificaram um atraso no desenvolvimento da criança nos primeiros 3 anos de vida, enquanto 1 participante identificou um atraso no desenvolvimento da criança entre 4 e 7 anos. Na faixa-etária de 0 a 3 anos é comum identificar algumas alterações em comunicação, interação social e cognição o que leva os pais a procurar ajuda médica. Conforme os critérios diagnósticos do DSM-5 (APA, 2013), as primeiras 
manifestações do TEA ocorrem antes do $36^{\circ}$ mês de idade, entretanto a maioria das crianças com TEA apresenta alguma alteração no seu desenvolvimento, entre 12 e 24 meses e em alguns casos, antes dos 12 meses. Em contraponto, Bosa (2006) afirma que o diagnóstico de TEA em crianças durante os anos pré-escolares é muito raro devido à falta de conhecimento do desenvolvimento esperado de uma criança. Atualmente o TEA é diagnosticado por meio da avaliação comportamental, testes neuropsicológicos vem contribindo para o diagnóstico precoce do TEA.

Em complemento à discussão Duarte et al. (2016) argumentam que não é possível ter um diagnóstico preciso do transtorno antes dos 3 anos, porém, podem constar traços do TEA. Os mesmos autores ainda comentam que deve ser iniciada a intervenção até estes sinais desaparecerem.

Apesar da dificuldade apresentada no diagnóstico precoce, deve-se buscar diagnosticar a criança com a maior brevidade possível, visto que quanto mais cedo conseguir o diagnóstico melhor para se iniciar o tratamento multidisciplinar com a criança. O diagnóstico tardio levará a criança a apresentar problemas mais graves de comunicação, interação social, como também poderá apresentar comportamentos agressivos.

\subsection{Conhecimento da família sobre o TEA}

Para entender se os pais realmente conheciam o Transtorno foram feitas duas perguntas. A primeira se eles sabiam o que era o TEA e na sequência pediu-se para que os participantes dissessem com suas palavras o que era o TEA.

Quando perguntado se sabiam o que era o TEA, todos os participantes alegaram saber o que era o TEA. O conhecimento do transtorno é necessário, pois é através dele que eles tomaram conhecimento de como, quando e onde começar o tratamento. O conhecimento sobre o TEA adveio de pesquisas particulares na "internet" no por meio do suporte formal, prestado por profissionais capacitados. Segundo Andrade e Teodoro (2012), este suporte tem como objetivo informar as famílias sobre o assunto através de informações e ferramentas de modo a auxiliar nos conhecimentos sobre o TEA e destacar as dificuldades que estarão por vir, ajudando assim a entender sobre o assunto em geral mostrando as necessidades da criança.

Carvalho-Filho et al. (2018) afirmam que o entendimento dos pais sobre o transtorno favorece o desenvolvimento do filho, permitindo que ele adquira independência e se sinta valorizado. Compreende-se assim que o conhecimento acerca do TEA pelos familiares é um fator facilitador da saúde emocional do filho. Em alguns casos além das pesquisas individuais, algumas famílias se apoiam na religião para suportar essa nova situação. Para Schmidt, Dell'aglio e Bosa (2007, p.130), "a busca de apoio social/religioso, adicionada ao bom nível de suporte formal e institucional percebidos, exerce uma importante função de suporte".

Portanto, adquirir conhecimento sobre o transtorno é garantir um apoio essencial para o filho com TEA, pois os pais passam, a saber, como agir perante as situações difíceis e auxiliar em seu tratamento, principalmente na inclusão social.

$\mathrm{Na}$ continuidade, perguntou-se aos participantes se sabiam dizer o que era o Transtorno de Espectro Autista. A pergunta teve a finalidade de identificar o quanto os participantes conheciam o transtorno, visto que todos alegaram conhecer. Entretanto, nas respostas verificaram-se entendimentos diferentes. Nas falas dos 
familiares foram levantadas 5 (cinco) subcategorias: alteração do comportamento, atraso no desenvolvimento, dificuldade na interação, atraso na fala e diagnóstico precoce. Discutiremos cada uma das subcategorias a seguir.

\subsection{Alteração do comportamento}

A alteração comportamental é uma das características do TEA, entretanto devese atentar para que as alterações de comportamento podem estar associadas a outras patologias. Observa-se essa subcategoria no trecho da fala do participante P.1 quando diz "Espectro Autista da mais em menino do que em menina. [...] é um transtorno que gera alteração comportamental". Segundo Pereira (2011, p.53)

A fisionomia do autista não demonstra qualquer alteração comportamental, sendo um dos motivos dos pais encontrarem dificuldade em encontrar um diagnóstico preciso ou suposição de possíveis problemas. Há três caminhos pelos quais as famílias passam: primeiro, conhecer o autismo; segundo, admitir o autismo e, por fim, buscar apoio de pessoas que convivam ou estão envolvidas com o autismo.

O TEA é um transtorno onde são caracterizadas alterações comportamentais, déficits qualitativos na interação social, déficits na comunicação, padrões de comportamento repetitivos e estereotipados, interesses e atividades limitados. Além disso, a criança com TEA pode apresentar agressividade (em relação a si e a terceiros) e sensibilidade aumentada a estímulos sensoriais (CANUT et al., 2014).

As alterações no comportamento podem ser entendidas, por alguns pais, como algo relacionado ao tratamento dado ao filho (mimando demais a criança) ou até mesmo a fase da criança. Para Gillberg (2005) as expressões faciais, gestos, postura corporal, entre outras é uma limitação da variabilidade de comportamentos. Esse entendimento equivocado dos pais, quando entendem que tais comportamentos fazem parte da fase ou é pirraça da criança, pode levar ao diagnóstico tardio do transtorno.

\subsection{Atraso no desenvolvimento}

Esta categoria foi identificada na fala do participante P.2 o qual enfatizou na sua resposta o atraso no desenvolvimento, conforme se pode observar no trecho da fala "O Autismo é um atraso no desenvolvimento [...]". O atraso no desenvolvimento é um dos motivos que leva os familiares a buscar ajuda sobre o que pode estar acontecendo com o seu filho. De acordo com Mansur et al. (2017, p. 36), "[...] é possível observar nas crianças com Autismo atraso nas aquisições do desenvolvimento global e ausência de comportamentos esperados para a idade cronológica." Segundo Gadia (2006), o autismo é definido como um transtorno complexo do desenvolvimento, do ponto de vista comportamental, com diferentes etiologias que se manifesta em graus de gravidade variados.

Cabe aos pais compreender, portanto, as reais necessidades do seu filho e aceitar principalmente suas diferenças. Assim, quanto mais cedo à criança for diagnosticada e iniciar o tratamento adequado, maiores serão as chances dela ter um desenvolvimento global satisfatório.

Verifica-se, portanto que o desenvolvimento da criança com TEA é lento e, se não for tratado da maneira correta, trará prejuízos no futuro. O diagnóstico precoce 
do TEA oportuniza o início de um tratamento adequado, contribuindo para o processo de aprendizagem e interação social da criança.

\subsection{Dificuldade na interação}

Esta categoria foi identificada na fala do participante P.3 quando enfatizou na sua resposta sobre a dificuldade de interação, fonforme pode-se observar no trecho a fala a seguir: "É quando a criança não interage com outras crianças, não olha nos olhos, não fala [...]". A dificuldade de interação desde pequeno é outra característica do Transtorno do Espectro Autista.

Silva e Ribeiro (2012) comentam que "as crianças autistas apresentam características de isolamento desde seus primeiros anos de vida, dificuldade em desenvolver relações pessoais, sendo esta observada precocemente e a dificuldade de vínculo com a figura materna". Essas crianças demonstram uma inaptidão para brincar em grupo ou para desenvolver laços de amizade. Normalmente, não participam de jogos cooperativos, demonstrando pouca emoção, pouca simpatia ou pouca empatia por outros.

Para Camargos Jr e Col (2005) o autismo "caracteriza-se por um déficit na interação social visualizado pela inabilidade em relacionar-se com o outro, usualmente combinado com déficits de linguagem e alterações de comportamento". A manifestação de problemas na interação social costuma ser um dos sinais mais típicos do transtorno autista.

Essa inaptidão pela interação social observada em crianças com TEA ocasiona o isolamento e dificuldade na fala da criança, dificultando ainda mais as relações intrafamiliares e a vida dos envolvidos.

\subsection{Atraso na fala}

O atraso na fala é o principal motivo de os pais buscarem assistência a um profissional. Esta categoria foi identificada na fala do participante P.4 o qual enfatizou que "É um transtorno neuro-social que tem como característica principal um possível atraso de fala [...]". A linguagem permite a busca de soluções alternativas, especialmente na negociação. Essas crianças precisam desenvolver habilidades para selecionar os melhores comportamentos que facilite o convívio social e a manifestação de seus sentimentos e desejos. É interessante que para uma melhor prática do fonoaudiólogo, este se utilize também de instrumentos que rastreiam problemas de comportamento (ZUÑIGA, 2005).

Para Whitman (2015), a linguagem de sinais para as crianças autistas podem ser uma das melhores formas de tratamento, dependendo de suas capacidades cognitivas, motoras e sensoriais, pois não há necessidade do uso de dispositivos físicos.

O atraso na fala afeta drasticamente o seu desenvolvimento social, desencadeando problemas futuros principalmente em seu desenvolvimento próprio, levando a pessimismo da família em relação ao seu futuro.

\subsection{Diagnóstico precoce}

O diagnóstico precoce é a melhor forma de tratamento, prevenindo a criança de eventuais problemas futuros. Está categoria foi identificada na fala de um 
participante P.5 que comentou "O autismo é um transtorno que é diagnósticado geralmente nos primeiros anos,...".

Para Canut et al (2014), a intervenção precoce é o melhor procedimento para permitir o desenvolvimento da criança, uma vez que quanto mais tardiamente a doença for abordada, mais consolidados estarão os sintomas. O diagnóstico precoce auxilia no desenvolvimento da criança, principalmente na questão cognitiva e social, sendo o melhor momento antes dos 3 anos.

Caracterizando os benefícios do diagnóstico precoce, Oliveira (2009, p. 279) afirma que "o diagnóstico precoce, bem como uma avaliação adequada e uma intervenção atempada e intensiva melhoram o prognóstico". O diagnóstico precoce propicia vantagens para a criança, pois melhora o seu desenvolvimento e a sua interação social.

Melhoria no desenvolvimento, na fala, na interação social é notável quando o diagnóstico é precoce, melhorando assim seu desenvolvimento. Portanto, a possibilidade de construir e aprender novas competências, melhorar comportamentos e corrigir os pontos fracos das crianças com autismo.

\subsection{A rejeição dos familiares}

No que tange à rejeição dos familiares verificou-se que em nenhuma família houve rejeição da criança com TEA por qualquer integrante. Neste estudo, verificase como é complicado receber a notícia de que o filho perfeito tão esperado não é como gostaríamos. O diagnóstico do TEA impacta na vida dos pais e dos familiares da criança. Nesses casos, sentimentos de angústia, negação, tristeza, luto afloram, levando, em alguns casos, até a exclusão do filho.

Muitos pais encontram dificuldades em relatar o diagnóstico do transtorno para o restante da família. Guzman et al. (2002) destacam que o medo e o constrangimento são comuns em relação ao diagnóstico do autismo, porém é de suma importância que eles recebam o apoio para que possam elaborar seus sentimentos em relação à criança para que possam auxiliá-la em seu desenvolvimento.

Apesar de não ter sido identificada rejeição, pode-se argumentar que muitos pais preferem negar a situação a aceitá-la. Buscaglia (2006) fala que é muito comum, inicialmente, a mãe não acreditar no diagnóstico e negar, de diversas maneiras, a si mesma e às demais pessoas que a cercam, a existência da deficiência. Nessa fase, a mãe não está preparada para conviver com algo dessa natureza, até porque estava esperando um bebê saudável e sem problemas. Algumas mães se lançam numa interminável busca por outros diagnósticos que possam negar aquela constatação inicial.

Este sentimento de rejeição pode vir ao longo do tempo. Hamer, Manente e Capelline (2014), relatam em seu artigo que a vida social associada aos recursos limitados da família de uma criança com TEA favorece o ressentimento, a raiva, a punição, a rejeição e o isolamento da criança no interior da família. Para Martins e Pires (2001) o autismo, comparado com outros transtornos e síndromes, é o mais difícil de gerir. Este sentimento de negação junto com muitos outros são naturais após o diagnóstico, principalmente em relação ao autismo. Em face da inexistência de exames que possam diagnosticar o TEA antes do parto, quando o diagnóstico surge no decorrer do desenvolvimento da criança, a família sofre um pesado impacto, 
pois todas as famílias vislumbram um filho saudável com um desenvolvimento esperado. Para Schwartz e Riedman (2009), a necessidade de culpar alguém pelos problemas dificulta que possam encarar a adversidade como um desafio.

Verifica-se, portanto que, o resultado do diagnóstico de TEA, gera um impacto muito forte no psicológico dos pais levando a um estágio de luto do filho perfeito. A aceitação do transtorno do filho é de suma importância para o convívio e a melhora na interação social melhorando assim o seu desenvolvimento.

\subsection{A importância dos pais para as crianças autistas}

Quando perguntado sobre a quão importante os pais se julgam para os filhos, verificou-se que em todos os participantes da pesquisa consideram-se uma figura importante. Segundo Maia Filho et al. (2016) a família exerce função importantíssima na vida de uma criança com TEA, pois o desenvolvimento da criança e a consequente melhoria na sua qualidade de vida, dependerá da capacidade de a família aceitar a condição da criança com esse transtorno e contribuir para o seu desenvolvimento.

Complementando, Oliveira (2015) ressalta em seu estudo a importância da família, em parceria com a escola, a fim de melhorar o desenvolvimento do filho. A participação ativa dos pais na vida escolar da criança, aumenta o seu nível de aprendizado.

Com isso, pode-se afirmar que a participação dos pais no tratamento das crianças com TEA contribuirá para um desenvolvimento da criança, oferecendo-Ihe uma maior qualidade de vida e autonomia.

\subsection{Reação da família ao diagnóstico}

Outra questão promovida aos participantes foi: Como a família reagiu ao diagnóstico? A partir das respostas forma obtidas 3 subcategorias: insegurança/assustados, negação e tristeza. Essas subcategorias serão detalhadas e discutidas a seguir.

\subsubsection{Insegurança/assustados}

Esta subcategoria foi identificada na fala do participante P.3 e P.4. Ambos apresentaram, nas falas, a sensação de medo por estar vivendo uma situação pouco conhecida e envolta de preconceitos. Tal subcategoria pode ser verificada no trecho da fala do participante P.3 ao dizer "Não tem um diagnóstico fechado, mas só de pensar que poderia ser ja desabou nosso mundo". Devido o diagnóstico de autismo não ter sido concluído, percebe-se a insegurança e medo perante o resultado do diagnóstico. Em relação á insegurança frente ao diagnóstico, Dantas et al. (2010) entendem que o nascimento é um momento de muita alegria para as famílias, contudo os sentimentos mudam quando nasce uma criança com deficiência. Este momento passa a ser de medo, insegurança e outros sentimentos. Complementando esse entendimento sobre os sentimentos, Guzman et al. (2002) comentam que o medo, insegurnaça e o constrangimento são emoçōes comuns aos pais da criança, uma vez que a experiência, a compreensão e as informações sobre essa síndrome ainda são limitadas. A falta de conhecimento sobre o transtorno leva os pais em busca de conhecimento a fim de auxiliar no desenvolvimento do filho.

$\mathrm{Na}$ fala do participante P.4 observa-se que o mesmo encontra-se assustado quando diz "Assustados e confusos por não conhecer o TEA", pois o desconhecimento 
e os estigmas que o transtorno tras consigo acarretam sensações e sentimentos negativos para os pais. Verifica-se ainda que a fragilidade da criança costuma ser uma situação assustadora para os pais e familiares, fazendo com que sintam medo de errar e demonstrem insegurança no cuidado (DANTAS et al, 2010).

Segundo a Organização Mundial de Saúde (2001), não se justifica a exclusão de pessoas com alguma doença mental ou transtorno da sua comunidade e que deve haver lugar para todos no mundo. Entretanto, muitas pessoas ainda se afastam assustadas de pessoas com deficiencia/transtorno ou simplesmente as ignoram, como se não pudessem compreender ou aceitar.

Entende-se, portanto que o susto ao receber a notícia do transtorno é em muitos casos, devido à falta de conhecimento do transtorno. Essa falta de conhecimento leva os pais a terem mais sentimentos negativos sobre o filho e seu futuro podendo levar a prejuízos ate mesmo aos familiares.

\subsubsection{Negação}

Esta categoria foi identificada na fala do participante P.2 quando comenta que "No começo não aceitaram, mas conforme o passar do tempo perceberam que tinham que ajudar para poder ele se desenvolver mais". Diante da fala é relatado a mudança de postura da familia. De acordo com Miller (1995) existem dois tipos de negação. Por um lado tem-se a negação escolhida e por outro a negação inconsciente. A primeira acontece quando os pais ignoram a deficiência do filho com a esperança que ela desapareça. No segundo caso, a negação é uma forma de não percepção da realidade. A negação acontece quando os pais negam o diagnóstico. Esta fase é mais evidente nas crianças com autismo, que faz com que os pais procurem, entre vários especialistas, diagnósticos diferentes.

Silva (2012) relata que ouvir o diagnóstico de autismo, mesmo que como uma hipótese, é muito difícil para os pais, por ser ainda um distúrbio muito marcante e as pessoas que o apresentam serem vítimas de muito preconceito. Na maioria das vezes, os pais passam por uma fase de negação, pois os mesmos cultivam sonhos e fantasias para o futuro de seus filhos.

Esta fase de negação caracteriza-se por uma defesa temporária, que mais tarde é substituída pela aceitação, ainda que parcial (PAÚL; FONSECA, 2001, p. 278). A negação é uma forma de lidar com a situação. No entanto, deverá estar consciente que passar por uma fase de raiva e negação não se pode traduzir numa perda de foco relativamente ao tratamento da criança.

Verifica-se que, com o diagnóstico do TEA estabelecido, os pais se encontram em uma situação em que, em um primeiro momento, não acreditam que o seu filho teria o transtorno. Esse medo dos pais acaba aumentando no ciclo social em que vivem fazendo com que muitos deles não relatem a situação vivida.

Em sua resposta, o participante P.5 comentou que recebeu o diagnóstico de forma natural, conforme o trecho da sua fala "De forma natural, já que na família foi, percebido muito cedo, que o desenvolvimento era diferente". Apesar da sua posição, entende-se que o medo dos pais em como encarar a situação perante a sociedade e restante da familia pode levá-los a não relatem a situação vivida (GAUDERER, 2003). Essa reação pode ser entendida como algo consciente ou inconsciente, sendo assim, haveria tambem uma negação de que algo estivesse acontecendo, daí dizer que foi natural. Ainda Miceli (2002) comenta que: 
[...] sentir dor não é natural, ainda que compreensível, e que ausência de dor é um direito do Paciente, deve-se agrupar esforços no sentindo de aliviar e controlar a sua dor, sabendo-a múltipla e dinâmica e adequando periodicamente o tratamento oferecido (p.370).

Todavia, deve-se considerar a possibilidade de a família ter notado algo de diferente com a criança e ter buscado conhecimento sobre o que poderia ser e como tratar o possível transtorno, conhecendo e preparando-se para as situações que porventura surgissem. Com isso, após receber o diagnóstico, a família ja estava preparada e já sabia como agir, não sofrendo da forma como outras familias sofreriam.

\subsubsection{Tristeza}

Esta categoria foi identifciada na fala do participante P.1 o qual enfatizou na sua resposta tristeza diante do transtorno, conforme se observa no trecho da fala "Muito tristes porque não sabia o que era o transtorno". O fato de não ter o diagnóstico logo ao nascer, gera uma tristeza profunda na família. Desde o momento em que descobrem a gravidez, os pais, fazem planos para os filhos. $O$ descobrimento de que a criança tem um transtorno do neurodesenvolvimento causa o chamado luto simbolico, pois o filho imaginado deixa de existir, causando culpa, frustração e tristeza. De acordo com Brunhara e Petean (1999), ocorrem sentimentos de decepção, frustração, mágoa e aflição na presença de um filho que não foi sonhado. Com isto, muitos pais precisam redefinir os seus planos e sonhos que tinham para os seus filhos e viver o processo de um luto simbólico com a perda do filho "perfeito", superando a perda das esperanças e dos sonhos que construíram para os seus filhos.

A tristeza é devida basicamente pela perda, luto, pelo filho perfeito e tão sonhado. $O$ autismo leva os sentimentos dos pais da alegria ate a tristeza em poucos meses devido as evidencias do transtorno só serem aparentes depois de alguns meses após o nascimento.

\subsection{A percepção dos pais quanto ao diagnóstico}

Nesta categoria os participantes apresentaram a percepção quanto ao diagnóstico dos filhos com TEA. Nas falas dos participantes identificaram-se as seguintes subcategorias: pessimismo e compreensivo.

\subsubsection{Pessimismo}

O pessimismo dos pais é identificado na fala do participante P.5 quando comenta que "[...] Há um certo pessimismo em relação ao prognostico". Os pais que recorrem a estratégias focadas na emoção apresentam maior estresse e possuem maior sentimento de culpa e falsas crenças sobre o TEA, assim como apresentam maior pessimismo relativamente ao prognóstico do filho (RIBEIRO, 2012). Os pais têm certo pessimismo em relação ao futuro do filho, especialmente em relação aos problemas que poderiam aparecer quando eles não estiverem mais por perto. Notase um grande estresse dos pais, principalmente da figura materna, devido aos cuidados com o filho, mas o maior medo é em relação a como o filho autista 
conseguira viver sem a sua presença e quem poderá ajudá-lo quando ele precisar de ajuda (HENN et al., 2008).

Verifica-se que este pessimismo é natural em pais de crianças com TEA, pois existe 0 medo de ter um filho vivendo em uma sociedade que ainda estigmatiza transtornos como o TEA, que sofrerá preconceito e discriminação. O medo dos pais mostra-se evidente quando, durante as falas comentam "será vai trabalhar?", "Como vão se desenvolver sem mim?", "Quem vai ajudar quando precisar?"

Frente a essas incertezas e medos, cabe aos profissionais da saúde que atuam na área, esclarecer todas as dúvidas dos pais, mostrando as possibilidades dessas crianças. Entende-se ainda que é necessário a desestigmatização do Transtorno de Espectro Autista, desconstruindo ideias distorcidas da sociedade sobre o transtorno.

Sobre o desconhecimento da sociedade a respeito do TEA, cabe ressaltar que em determinado momento da fala, o participante P.3 comentou que "Por eu não comentar e por não ter um diagnóstico fechado, as pessoas olham e pensam se tratar de uma criança mimada". Devido à falta de conhecimento sobre o assunto, muitas pessoas tomam conclusões precipitadas sobre diversos assuntos, apresentando um juizo preconcebido que se manifesta, geralmente, por atitudes discriminatorias perante as pessoas consideradas diferentes ou "estranhos", com no caso do autista (PAIVA JUNIOR, 2012).

\subsubsection{Compreensivo}

A compreensão da família de que tem uma pessoa que necessita de sua ajuda é essencial para auxiliar em seu desenvolvimento. Os participantes P.2 e P.4 em suas falas comentam que "[...] a própria família passou a ajudar, porque antes achavam que era fase, [...] perceberam que tinham que fazer algo diferente". (P. 2) e "No meio onde convivo as pessoas entendem o transtorno dele e de alguma forma compreendem todo processo". (P. 4)

Para Fávero (2005), o processo de compreensão da família, passa por etapas onde dentre elas são: processo de peregrinação em hospitais e profissionais de saúde, luto, dificuldades em lidar com a criança, as mudanças e as sobrecargas familiares e o desamparo dos pais em relação à perspectiva do futuro do filho. Constata-se, portanto, que o apoio da família aliado a oportunidades de educação, com profissionais capacitados, as crianças, mesmo que com algumas limitações cognitivas, conseguem desenvolver uma gama de habilidades. (HENN, et al., 2008)

Entretanto, observa-se ainda que existam pais que, por não terem conhecimento, veem os primeiros sinais do transtorno como alguma desobediência ou rebeldia. Para Perryman (2009) os pais acabam atribuindo aos primeiros sinais do transtorno, explicações de que pensavam que era uma criança desobediente, tinha uma personalidade difícil ou era mimada.

O apoio e a compreensão dos familiares são de suma importância para o desenvolvimento da criança com TEA, aumentando assim suas chances de um desenvolvimento com maior qualidade de vida e melhorias em sua comunicação e interação social.

\subsection{Dificuldades encontradas pelos pais no tratamento}

A confirmação do transtorno já é um choque. Após este momento a família precisa manter o equilíbrio psicológico para compreender a necessidade do filho e as 
dificuldades que surgirão no decorrer de suas vidas. A família deve entender que a criança com TEA necessita de um tratamento adequado, por uma equipe multidisciplinar, e ter o apoio da família em casa e durante o tratamento. Após responderem às perguntas levantaram-se as subcategorias falta de profissionais e 0 comportamento da criança.

\subsection{Falta de profissionais}

O número de profissionais especialistas em Transtorno de Espectro Autista na cidade de Manaus é reduzido, principalmente na área da psicologia. Existem poucas clinicas com uma equipe multidisciplinar para atender e acompanhar crianças com esse transtorno. A falta de profissionais é identificada na fala do participante P.4 ao comentar que "Instituiçōes de apoio a pessoas com TEA, poucos profissionais especializados na area, $[\ldots]$ ", do participante P.3 "Encontrar terapia ocupacional [...], poucos psicólogos". Conforme Visani e Rabello (2012) argumentam que a falta de conhecimento e de autonomia por parte de profissionais de saúde em relação ao diagnóstico de autismo, revelam a necessidade de investimento na capacitação de profissionais da saúde, visando melhorar a qualidade da assistência voltada ao acompanhamento do desenvolvimento infantil.

Ribeiro (2012) comenta que a falta e/ou escassez de profissionais especializados e os estereótipos da sociedade em relação ao autismo, causam um alto nivel de estresse aos pais. O mesmo autor ainda comenta que esse alto nivel de estresse pode ser gerado em consequência de diagnóstico impreciso e cuidados inadequados, fato argumentado pelo participante P.5 ao dizer que uma de suas preocupações era "[...] poucos profissionais que realmente entendem do assunto". (P. 5)

Verifica-se, portanto que a falta de profissionais prejudica tanto as crianças, quanto os pais, pois eles acabam tendo falta de informação sobre o transtorno, além de um tratamento precario e deficitário. O acompanhamento de profissionais capacitados é muito importante para auxiliar no convívio social e escolar da criança com TEA.

\subsection{Comportamento da criança}

O TEA possui características bem próprias, a existência de comportamentos estereotipados é uma dessas características, além do pouco contato fisico e não gostarem de barulho. O convívio pode se tornar muito desgastante se a família não for preparada e não houver cumplicidade no tratamento. No trecho da fala do participante P.2 quando diz, "[...] ele não gosta de lugares fechados e nem que as pessoas abraçassem ele", ao alegar que seria uma dificuldade no tratamento, mostra bem a necessidade de preparar os pais de forma a fazer com que esses contribuam para o tratamento e entendam o Transtorno.

Quanto a essa questão, Schmidt, Dell'Aglio e Bosa (2007, p. 182) dizem que "as características próprias do comportamento de pessoas com autismo, somadas à severidade do transtorno, podem constituir estressores em potencial para familiares".

O tratamento do TEA só terá uma evolução saudavel com a participação da familia e para isso faz-se necessária a preparação desses pais, bem como o acompanhamento deles. De acordo com Ribeiro (2012) a confirmação do diagnóstico 
de autismo implica a família, não somente na prestação de cuidados diários permanentes às crianças, mas também na aquisição de competências e habilidades para lidar com os sintomas e comportamentos.

Conviver com outros indivíduos é complicado e até mesmo com a família, visto que acabam não deixando que as pessoas entrem no mundo dele, pois a percepção dele é diferente.

\section{Considerações finais}

O diagnóstico de TEA é um grande impacto para os pais, pois a idealização da criança perfeita se depara com o real e os genitores acabam vivenciando o luto pelo filho perfeito perdido. O diagnóstico desse transtorno acaba sendo um dos piores para aceitação dos pais, pois o diagnóstico é demorado e só pode ser feito após meses do nascimento. Durante esse tempo a família a passar por um período de desejos e sonhos para o filho e, logo após, tudo reverte com o resultado do diagnóstico.

Sentimento de negação, tristeza, magoa e até depressão caem sobre os pais. Por isso, a importância do tratamento para os pais, pois será nesse acompanhamento que eles abrirão suas mentes em relação ao autismo, tendo o conhecimento necessário para contribuir no desenvolvimento da criança.

A busca por profissionais qualificados para diagnosticar com precisão e de forma precoce o transtorno vem acontecendo de forma mais rápida devido a divulgações e também ao dia mundial do autista, dia este que a ONU estipulou com o intuito de promover maior conhecimento sobre o transtorno. Isto auxilia na diminuição dos paradigmas e incentiva novos profissionais a se focarem no assunto.

Por fim, vale destacar que tal assunto requer a realização de outras pesquisas a fim de expandir o conhecimento e fazer com que se encontrem novos tratamentos e acompanhamentos para o TEA, além de tornar o assunto aberto para a população, desestigmatizando o transtorno e oportunizando o indivíduo com TEA uma inserção social sadia, sem preconceitos e discriminações.

\section{REFERÊNCIAS}

ASSOCIAÇÃO AMERICANA DE PSIQUIATRIA. Manual diagnóstico e estatístico de transtornos mentais: DSM-V. Trad. Maria Inês. Porto alegre: Artmed, 2013.

ANDRADE, Aline Abreu; TEODORO, Maycoln. Lêoni. Martins. Família e Autismo: Uma Revisão da Literatura. Contextos Clínicos, São Leopoldo, v 05, n. 2, p. 133142, 2012.

BONI, Valdete; QUARESMA, Sílvia Jurema. Aprendendo a entrevistar: como fazer entrevista em Ciências Sociais. Em Tese, Florianópolis, v. 2, n. 1, p. 68-80, jan/jul. 2005.

BOSA, Cleonice Alves. Autismo: Intervenções Psicoeducacionais. Revista Brasileira de Psiquiatria. São Paulo, v. 28, n.1, p. 47-48, 2006. 
BRUNHARA, Fabíola; PETEAN, Eucia Beatriz Lopes. Mães e filhos especiais: reações, sentimentos e explicações à deficiência da criança. Paideia, Ribeirão Preto, v.9, n.16, p. 31-40, 1999. Disponível em:

http://www.scielo.br/pdf/paideia/v9n16/04.pdf . Acesso em 10 set. 2020.

BUSCAGLIA, Leo. Os deficientes e seus Pais: um desafio ao aconselhamento. Tradução de Raquel Mendes. 5 ed. Rio de Janeiro: RECORD, p. 313, 2006.

CAMARGOS Jr, Walter (cols). Transtornos invasivos do desenvolvimento. 2. ed. Brasilia-DF: $3^{\circ}$ Milênio, 2005.

CAMPOS, Larriane Karen de. Comparação entre o perfil escolar e as habilidades cognitivas e de linguagem de crianças e adolescentes do espectro do autismo. Dissertação (Mestrado em Ciências da Reabilitação) Faculdade de Medicina - Universidade de São Paulo, 2015.

CANUT, Ana Carolina Andrade et al. Diagnóstico Precoce do Autismo: Relato de Caso. Revista de Medicina e Saúde de Brasília, Brasília-DF, v. 03, n. 1, p. 3137, 2014.

CARVALHO-FILHO, Francidalma Soares Sousa et al. Entendimento do espectro autista por pais/cuidadores - estudo descritivo. Rev. Cient. Sena Aires, Goiania, v. 07, n.2, p. 105-116, 2018.

CORRÊA, Hamilton Luiz; HOURNEAUX Jr, Flavio. Sistemas de mensuração e avaliação de desempenho organizacional: estudo de casos no setor químico no Brasil. Revista Contabilidade \& Finanças, São Paulo, v. 19, n. 48, p. 1-13, Set/Dez. 2008.

MAIA FILHO, Antonio Luiz Martins et al. A Importância da Família no Cuidado da Criança Autista. Rev. Saúde em Foco. Teresina. v. 03, n. 1, p. 66-83, 2016.

CRAMER, Bertrand; PALACIO-ESPASA, Francisco. Técnicas psicoterápicas mãe/bebê. Porto Alegre: Artmed, 1993.

DANTAS, Meryelli Santos de Araújo et al. O Impacto do Diagnóstico de Paralisia Cerebral Para a Família. Texto Contexto Enferm. Florianópolis, v. 19, n. 2, p. 229-237, 2010.

DUARTE, Cíntia Perez et al. Diagnóstico e Intervenção Precoce no Transtorno do Espectro do Autismo. Autismo - Vivencias e Caminhos. In: CAMINHA, Vera Lucia et al. (Org). Autismo: Vivencias e caminhos. São Paulo: Blucher, 2016, p. 45-56.

FÁVERO, Maria Ângela Bravo. Trajetória e Sobrecarga Emocional da Família de Crianças Autistas: Relatos Maternos. Dissertação (Mestrado em Psicologia) Universidade de São Paulo, Ribeirão Preto. 2005. 
GADIA, Carlos. Aprendizagem e autismo: transtornos da aprendizagem. Porto Alegre: Artmed, 2006.

GAUDERER, Christian. Autismo e outros atrasos do desenvolvimento. Guia prático para pais e profissionais. 2 ed. Revista e Ampliada. Rio de Janeiro: Revinter, 2003.

GILLBERG, Christopher. Transtorno do Espectro Autista. XXIII Congresso Brasileiro de Psiquiatria. Diretrizes em psiquiatria: nova clínica/novas instituições/novas intervenções. Anais..., Belo Horizonte, 2005. Palestra. Disponível em https://www.ama.org.br/site/wpcontent/uploads/2017/08/DrChristopherGillbergnoBrasil.pdf. Acesso em 27 de Abr 2020.

GUZMAN, Helen Messias da Silva et al. Autismo: questões de tratamento e consequências na família. Iniciação Científica Cesumar, Maringá, v. 4, n. 1, p. 63-8, mar./jul. 2002.

HAMER, Bruna Laselva; MANENTE, Milena Valelongo; CAPELLÍNE, Vera Lúcia Messias Fialho. Autismo e Família: Revisão Bibliográfica em Bases de Dados Nacionais. Rev. Psicopedagogia. São Paulo -SP,v. 31, n. 95, p. 169-177, 2014.

HENN, Camila Guedes et al. A Família no Contexto da Síndrome de Down: Revisando a Literatura. Psicologia em Estudo, Maringá, v. 13, n. 3, p. 485-493, 2008.

KOEGEL, Robert (Cols). Consistent Stress Profiles in Mothers of Children With Autism. Journal of Autism and Developmental Disorders. v.22, n. 2, p. 205215, 1992.

MANNONI, Maud. Educação impossível. Rio de Janeiro: Francisco Alves, 1988.

MANSUR, Odila Maria Ferreira de Carvalho. Sinais de alerta para Transtorno do Espectro do Autismo em crianças de 0 a 3 anos. Revista Científica da FMC, Campos, v. 12, n 3, p. 34-40. Dez. 2017.

MARTINS, Dilair; PIRES, Antônio. Autismo Infantil e Comportamento Maternal. In PIRES, Antônio. Crianças (e Pais) em Risco. 2001. p. 233-274.

MICELI, Ana Valéria Paranhos. Dor crônica e subjetividade em oncologia. Revista Brasileira de Cancerologia, v.43, n.8, p.363-73, 2002.

MILLER, Nancy. Ninguém é Perfeito. Vivendo e Crescendo com Crianças que têm Necessidades Especiais. Campinas: Papirus, 1995.

MINAYO, Maria Cecília Mynayo; SANCHES, Odécio. Quantitativo-Qualitativo: Oposição ou Complementaridade? Cad. Saúde Pública, Rio de Janeiro, v. 9, n.3, p. 239-262, jul/set, 1993. 
OLIVEIRA, Andreia Cosme. O papel da família no processo de inclusão escolar do aluno com Transtorno do Espectro Autista. Trabalho de Conclusão de Curso de Especialização. Universidade de Brasília. Brasília-DF, 2015.

OLIVEIRA, Guiomar. Autismo: Diagnóstico e Orientação Parte I - Vigilância, Rastreio e Orientação nos Cuidados Primários de Saúde. Acta Pediátrica Portuguesa, v. 40, n. 6, p. 278-287, 2009.

ORGANIZAÇÃO MUNDIAL DE SAÚDE. Saúde Mental: Nova Concepção, nova esperança. Genebra: OMS, 2001.

PAIVA JUNIOR, Francisco. Preconceito x Informação. 2012. Disponível em https://www.revistaautismo.com.br/RevistaAutismo002.pdf. Acesso em 20 mai 20.

COLL, César; MARCHESI, Álvaro; PALACIOS; Jésus (cols). Desenvolvimento Psicológico e Educação. Porto Alegre: Artmed, 2004.

PAÚL, Constança; FONSECA, Antônio. Psicossociologia da Saúde. Manuais Universitários. Lisboa: Climepsi, 2001.

PEREIRA, Cyelle Carmem Vasconcelos. Autismo e Família: Participação dos Pais no Desenvolvimento dos Filhos Autistas. Facene/Facene, João Pessoa, v. 9, n. 2, p. 51-58, 2011.

PERRYMAN, Twyla Yatai. Investigando disparidades na era do diagnóstico do Transtorno de Espectro Autista. Dissertação (Faculdade de medicina) Universidade da Carolina do Norte em Chapel Hill, 2009.

RIBEIRO, Nadia Maria. Viver como Autismo: Necessidades dos Pais de Crianças com Perturbação do Espectro do Autismo. Porto: Instituto de Ciências Biomédicas Abel Salazar, 2012.

SCHMIDT, Carlo; DELL'AGLIO, Débora Dalbosco; BOSA, Cleonice Alves. Estratégias de Coping de Mães de Portadores de Autismo: Lidando com Dificuldades e com a Emoção. Psicologia: Reflexão e Crítica, Porto Alegre, v. 21, n. 1, p. 124-131, 2007.

SCHWARTZ, Mary; RIEDMANN, Agnes. Marriages and families: Making choices in a diverse society. Belmont, CA: Thomson, 2009.

SILVA, Ana Beatriz Barbosa. Mundo Singular: Entenda o Autismo. Rio de Janeiro: Objetiva, 2012.

SILVA, Eliene Batista Alves da; RIBEIRO, Maysa Ferreira. Aprendendo a ser mãe de uma criança autista. Estudos, Goiânia, v.39, n.4, p. 579-589, out/dez. 2012 
SPROVIERI, Mario. Família, autismo e sociedade. In: ASSUMPÇÃO Jr, Francisco Baptista; SCHWARTZMAN, Jacques. Autismo infantil. São Paulo: Memnon, 1995. p. 264-276.

TEIXEIRA, Enise Barth. A análise de dados na pesquisa científica: importância e desafios em estudos organizacionais. Desenvolvimento em Questão, v. 1, n. 2, p. $177-201,2003$.

VENDRUSCULO, Larissa Ester Bartz. Descoberta da deficiência do filho: o luto e a elaboração dos pais. Trabalho de Conclusão de Curso (Faculdade de psicologia) Universidade Regional do Noroeste do estado do Rio Grande do Sul, 2014.

VISANI, Paola; RABELLO, Silvana. Considerações sobre o diagnóstico precoce na clinica do autismo e das psicoses infantis. Rev. Latinoam-Psicopat., v. 15, n. 2, p. 293-308, 2012.

WHITMAN, Thomas. O desenvolvimento do autismo. São Paulo: M.Books, 2015.

ZUÑIGA, Amanda Farias. Descrição e tratamento dos transtornos da comunicação e da linguagem. In: CABALLO, Vicente; SIMON, Miguel Angel (Orgs). Manual de Psicologia Clínica Infantil e do Adolescente: Transtornos Específicos. Santos: Livraria Santos, 2005. 